\title{
INTERFACE DO SETOR PRODUTIVO DE CAMPO DO MEIO-MG COM A RESERVA LEGAL
}

João Batista NEVES

Mestre em Sistemas de Produção na Agropecuária da Universidade José do Rosário Vellano - UNIFENAS, Alfenas, MG. jbatistaneves@yahoo.com.br

Recebido em: 10/02/2013 - Aprovado em: 15/07/2013 - Disponibilizado em: 15/08/2013

\section{RESUMO}

A reserva legal pode ser entendida como um limite encontrado pelo legislador para delinear a propriedade, observando a prevalência do interesse público sobre o particular, pois aquele representa os anseios de toda a coletividade. Com o intuito de verificar a obrigatoriedade (conhecimento) da instituição da Reserva Legal no agronegócio nas propriedades rurais do município de Campo do Meio-MG, foram aplicados 74 questionários aos pequenos proprietários rurais, com questões específicas sobre o problema levantado de modo a alcançar o objetivo deste trabalho. Foi realizada uma análise exploratória dos dados no período entre os dias 16 e 24 de abril de 2012, com a finalidade de extrair informações sobre fatores que limitaram a implantação das reservas legais ambientais. Os dados foram tabulados no software Microsoft Office Excel, 2007 e organizados por meio do gráfico de setores. Dos pontos para a resistência da implantação é o baixo índice de conhecimento. Outro ponto relevante para a não implantação da Reserva Legal é por serem produtores mais velhos e resistentes a mudanças e também por serem pequenos produtores possuindo máximo até 4 hectares de propriedade e acreditando que serão prejudicados com a implantação Reserva Legal. Analisando as declarações dos produtores rurais, observou-se que existem poucos remanescentes florestais em todas as propriedades que participaram da pesquisa. Assim, mostra-se a necessidade de haver um incentivo para com o produtor, para, quem sabe assim, o mesmo possa efetivar as áreas correspondentes à legislação, e, dessa forma, não apenas cumprindo com a lei, mas também preservando o ambiente.

Palavras-chave: Reserva Legal. Meio Ambiente. Proprietários Rurais. Legislação. Conhecimento.

\section{ABSTRACT}

The legal reserve may be understood as a limit found by the legislator to delineate the property, noting the prevalence of public interest about the particular, for he represents the aspirations of the whole community. In order to verify the requirement (knowledge) of the institution of the Legal reserve in agribusiness in rural municipality of Field properties of MG, 74 were applied questionnaires to small landowners, with specific questions about the problem raised in order to achieve the objective of this work. An exploratory analysis of the data in the period between days 16 and April 24 , 2012, in order to extract information about factors that have limited the implementation of the environmental legal reserves. The data was tabulated in Excel, Microsoft Office 2007 software and organized through the chart of sectors. Of points for resistance of deployment is the low level of knowledge. Another point relevant to the implementation of the Legal reserve is not because they are older producers and resistant to change and also because they are small producers owning more than 4 acres of property and believing that they will be harmed by deploying Legal reserve. Analyzing the declarations of the farmers, it was observed that there are few forest remnants in all properties that participated in the research. Thus, shows the need for an incentive for the producer to, who knows well, it can make the areas corresponding to the legislation, and, in this way, not only complying with the law, but also preserving the environment.

Keywords: Legal reserve. Environment. Landowners. Legislation. Knowledge. 


\section{INTRODUÇÃO}

O equilíbrio entre a

desenvolvimento econômico sempre foi objeto de discussão entre os ambientalistas, os agropecuaristas e a população em geral. Isso ocorre porque o crescimento econômico, entre outros aspectos, tem exigido cada vez mais um desenvolvimento sustentável, ou seja, um processo pelo qual a economia consegue crescer simultaneamente com a redução das desigualdades sociais e com a preservação do meio ambiente.

Nesse contexto, insere-se a preocupação em preservar parte das matas nas propriedades rurais, inserindo-se aqui o instituto da Reserva Legal, cujo objetivo é o de não só preservar parte da cobertura arbórea existente na propriedade, bem como, recompor o que já se encontra degradado. O Código Florestal (Lei 12651/12) em seu art. $3^{\circ}$ descreve:

Reserva Legal: área localizada no interior de uma propriedade ou posse rural, delimitada nos termos do art. 12, com a função de assegurar o uso econômico de modo sustentável dos recursos naturais do imóvel rural, auxiliar a conservação e a reabilitação dos processos ecológicos e promover a conservação da biodiversidade, bem como o abrigo e a proteção de fauna silvestre e da flora nativa.

Vale lembrar que a terra é um bem de produção por excelência, fonte de riquezas. Além disso, trata-se de parte do meio ambiente onde vive o ser humano, ou seja, a terra é o local das relações entre os homens e o meio ambiente.

Não se pode esquecer de que a terra é um bem finito e sua conservação e manuseio exigem racionalidade e bom senso. A manutenção da natureza, dos animais e das plantas é questão primordial para a sobrevivência da espécie humana no planeta. A propriedade rural deve cumprir a sua função social para que, explorada de forma eficaz, possa contribuir para o bem-estar não apenas de seu titular, mas, por meio de níveis satisfatórios de produtividade e, sobretudo de relações de trabalho justas, assegurar a justiça social de toda a comunidade na qual está inserida. Considerando-se a importância da preservação ambiental, objetivou-se com este trabalho levantar a situação do cumprimento da legislação florestal com relação à legislação pertinente e investigar o grau de conhecimento dos produtores rurais em relação à obrigatoriedade da instituição da Reserva Florestal Legal nas propriedades rurais do município de Campo do Meio - MG. 


$$
\text { O texto aprovado }
$$

praticamente manteve as distâncias do Código Florestal até então em vigor, ou seja, deve se manter protegido um raio mínimo de 50 metros ao redor das nascentes e "olhos d'água", ainda que sequem em alguns períodos do ano. Por sua vez, as faixas de proteção nas margens dos rios continuam exatamente as mesmas da lei vigente hoje (30 a 500 metros dependendo da largura do rio), mas passam a sere medidas a partir do leito regular e não do leito maior nos períodos de cheia. A exceção é para os rios estreitos com até dez metros de largura, para os quais o novo texto permitiu, para aquelas margens de rio totalmente desmatadas, a recomposição de 15 metros. Assim, para rios de até 10m de largura onde a APP está preservada continua valendo o limite de $30 \mathrm{~m}$; para rios totalmente sem mata ciliar o produtor ainda está obrigado a recompor $15 \mathrm{~m}$ (SENADO FEDERAL DO BRASIL, 2011).

\section{O novo Código Florestal} aprovado dispensou os imóveis com até quatro módulos fiscais da obrigatoriedade de cumprimento integral da área de reserva legal. No texto, tais propriedades deverão manter a área de reserva legal que detinham em 22 de julho de 2008.
No cálculo da Reserva Legal, poderão ser computados os plantios de árvores frutíferas, ornamentais ou industriais, compostos por espécies exóticas, cultivadas em sistema intercalar ou em consórcio com espécies nativas da região em sistemas agroflorestais.

Além disso, para definir a área destinada à reserva legal, o proprietário poderá considerar integralmente a área de preservação permanente (APP) no cálculo se isso não provocar novo desmatamento, se a APP estiver conservada ou em recuperação e se o imóvel estiver registrado no Cadastro Ambiental Rural (CAR). Por sua vez, para a inscrição da reserva legal no CAR, basta a apresentação de planta e de memorial descritivo, contendo a indicação das coordenadas geográficas com pelo menos um ponto de amarração.

Para registro da reserva legal no Cadastro Ambiental Rural, o órgão ambiental ficará responsável técnica e financeiramente pela captação de coordenadas geográficas.

A Lei 12.651/2012 que dispõe sobre a proteção da vegetação nativa conceitua como sendo Reserva Legal:

área localizada no interior de uma propriedade ou posse rural, delimitada nos termos do art. 12, com a função de assegurar o uso 
econômico de modo sustentável dos recursos naturais do imóvel rural, auxiliar a conservação e a reabilitação dos processos ecológicos e promover a conservação da biodiversidade, bem como o abrigo e a proteção de fauna silvestre e da flora nativa.

Tal legislação enfatizou o tema Reserva Legal, tratado do mesmo em um capítulo próprio (capítulo IV) com três seções.

Estabelece o artigo 12 desse diploma legal que: “Todo imóvel rural deve manter área com cobertura de vegetação nativa, a título de Reserva Legal, sem prejuízo da aplicação das normas sobre as Áreas de Preservação Permanente". Assim, prevê a legislação que estão sujeitos à implantação da Reserva Legal apenas imóveis rurais, contudo o mesmo diploma legal, posteriormente, se contradiz ao dispor, no artigo 19, que:

A inserção do imóvel rural em perímetro urbano definido mediante lei municipal não desobriga o proprietário ou posseiro da manutenção da área de Reserva Legal, que só será extinta concomitantemente ao registro do parcelamento do solo para fins urbanos aprovado segundo a legislação específica e consoante as diretrizes do plano diretor de que trata o $\S 1^{\circ}$ do art. 182 da Constituição Federal.

Essa legislação, além de estabelecer que o proprietário deva manter na terra vegetação nativa (artigos 12 e 17) e dispor acerca da porcentagem que deve ser separada na propriedade a título de reserva legal (artigo 12 caput), ainda prevê, no artigo 14, que a localização da reserva legal no imóvel rural deverá levar em consideração estudos e critérios sobre:

I - o plano de bacia hidrográfica II - o Zoneamento EcológicoEconômico;

III - a formação de corredores ecológicos com outra Reserva Legal, com Área de Preservação Permanente, com Unidade de Conservação ou com outra área legalmente protegida;

IV - as áreas de maior importância para a conservação da biodiversidade;

$\mathrm{V}$ - as áreas de maior fragilidade ambiental.

O rol previsto no supramencionado artigo 14 é cumulativo, ou seja, todos os requisitos previstos em seus incisos devem ser cumpridos. O simples cumprimento alternado ou de um dos requisitos não autoriza a aprovação da localização da reserva legal (SIFUENTES, 2012).

O parágrafo primeiro diz que um órgão estadual integrante do Sistema Nacional do Meio Ambiente (SISNAMA) ou instituição por ele habilitada será responsabilizada por aprovar a localização da Reserva Legal.

Assim, além de perder parte do seu imóvel rural, mantendo vegetação nativa, o proprietário de imóvel rural fica sujeito à aprovação da localização da área pelo órgão estadual competente. 
Os estudos e critérios estabelecidos pelo artigo 14 podem considerar como apta a preservação, título de Reserva Legal, justamente a área de maior produtividade do imóvel rural, o que acarretaria sérios prejuízos ao proprietário, pois não poderia ali plantar ou criar animais, que por muitas vezes garante o sustento próprio e de sua família (SIFUENTES, 2012).

\section{METODOLOGIA}

\section{Caracterização do local de pesquisa}

O município de Campo do Meio, Distrito criado com sede no povoado de Campo do Meio e, com esta mesma denominação, por Lei Estadual $n^{\circ} 843$, de 7 de setembro de 1923, foi desmembrado do distrito da sede do Município de Campos Gerais. Por efeito da citada Lei, o Distrito de Campo do Meio figura no Município de Campos Gerais.

O município de Campo do Meio foi instalado em 2 de março de 1924. Elevado à categoria de município pela Lei $\mathrm{n}^{\circ} 336$, de 27 de dezembro de 1948, que fixou o quadro territorial para 19491953, composto apenas de um Distrito, Campo do Meio.

Localizado no Sul de Minas, com uma área de 273,8 Km2, altitude máxima de $1.083 \mathrm{~m}$ acima do nível do mar, na Serra Santa Catarina (Serrinha do Amargoso) e altitude média - 780m A Represa de Furnas é ponto central da cidade, em torno da qual distribuem-se 10 bairros rurais. Campo do Meio possui o número de módulos fiscal agrícola de 26 (IBGE, 2012).

\section{Levantamento de dados}

Com o intuito de verificar a interface do setor produtivo de Campo do Meio- MG com a Reserva Legal, foram aplicados 74 questionários (Anexo 1) junto aos pequenos proprietários rurais, cuja definição está de acordo com o Sebrae (2012).

O questionário elaborado contém questões específicas sobre o problema proposto de modo a alcançar o objetivo deste trabalho que foi levantar a situação do cumprimento da legislação florestal com relação à legislação pertinente $\mathrm{e}$ investigar o grau de conhecimento dos produtores rurais em relação à obrigatoriedade da instituição da Reserva Florestal Legal nas propriedades rurais do município de Campo do Meio - MG. Vale ressaltar que todo questionário foi, em um primeiro momento, explicado de forma calma e didática para compreensão de todos os proprietários entrevistados.

Foi feita uma análise exploratória dos dados com a finalidade de extrair 
informações de caráter socioeconômico relacionando às questões de interesse contidas no questionário.

No período compreendido entre os dias 16 e 24 de abril de 2012, foram aplicados 74 questionários aos produtores rurais de Campo do MeioMG, com a finalidade de extrair informações sobre fatores que limitaram a implantação das reservas legais ambientais. Durante esse tempo, pesquisaram-se vários agricultores em diversas regiões como Capoeirão; Capim Roxo; Retirinho; Fazenda Santa Terezinha; Limeira; Olhos D’Água; Amargoso; Pedra Branca; Caiana; Regiões da Antiga Cerâmica de Campo do Meio; Campos das Flores, entre outras pequenas regiões rurais de Campo do Meio. Algumas regiões não foram exploradas, pois são pertencentes à antiga Usina Ariadnópolis e nela existem muitas famílias que tomaram posse, mas não são proprietárias da terra (Movimento dos Sem-Terra).

Com a aplicação do questionário, observou-se o receio dos entrevistados de prestarem informações necessárias com veracidade.

Os dados obtidos por meio da referida pesquisa foram tabulados no software Microsoft Office Excel, 2007 e organizados por meio do gráfico de setores.

\section{RESULTADOS E DISCUSSÃO}

É interessante destacar que, dos entrevistados, $73 \%$ são do gênero masculino e $27 \%$, do gênero feminino.

Com relação à faixa etária dos proprietários rurais, verificou-se que $54 \%$ possuem de 26 a 50 anos; $35 \%$, acima de 50 anos; 6\%, de 18 a 25 anos e $5 \%$ dos entrevistados não informaram sua idade. Cerca de $81 \%$ são casados; $8 \%$ são solteiros; $6 \%$, outros e $5 \%$ não relataram o estado civil.

Verificou-se que $40 \%$ dos entrevistados possuem o $1^{\circ}$ grau incompleto; $23 \%$ possuem o $2^{\circ}$ grau completo; $18 \%$ possuem o $2^{\circ}$ grau incompleto; $16 \%$ apenas o $1^{\circ}$ grau completo e $3 \%$ possuem nível superior.

Ao serem questionados sobre residir ou não na propriedade rural, observou-se que $57 \%$ dos entrevistados residem na propriedade rural e $43 \%$ não residem na propriedade, apenas trabalham nos sítios e nas fazendas. Essa informação nos permite analisar o envolvimento dos moradores com a reserva legal, assim como a atitude e os usos no meio local, uma vez que nem todos os nascidos no local podem ter vivido ali durante toda a sua vida. $\mathrm{Ou}$ seja, o convívio diário com os 
moradores, presenciando o relato deles e convivendo com a importância da preservação do meio ambiente, a maioria $57 \%$ prefere continuar residindo em suas propriedades rurais.

Dos $57 \%$ dos proprietários que residem na propriedade rural, o grupo familiar é composto de $37 \%$ de 2 a 3 pessoas;, $17 \%$, de 4 a 5 pessoas e $3 \%$, de 6 a 7 pessoas. Observou-se que 37\% do grupo familiar residente nas propriedades rurais possuem de 2 a 3 pessoas. Pôde-se verificar também que $78 \%$ dos proprietários rurais não possuem funcionários caracterizando uma agricultura familiar.

Segundo Rodrigues (2007), as relações familiares e com o lugar, em geral, são tecidas na mesma porção de terra onde viveram seus antepassados. $\mathrm{Na}$ pesquisa (resposta do questionário) em pauta, em relação ao tipo de associação que os proprietários entrevistados possuem, observou-se que $58 \%$ dos pequenos produtores são associados a uma cooperativa enquanto que $42 \%$ não são. Em relação à assistência técnica em suas propriedades, $65 \%$ a recebem periodicamente ao passo que para $35 \%$, tal atividade não se faz presente.

Dos proprietários rurais entrevistados, $66 \%$ não possuem computador em suas propriedades; $33 \%$ possuem e utilizam e 1\% não informou. Dos $33 \%$ dos proprietários rurais que utilizam computador, $21 \%$ possuem internet.

A televisão com $75 \%$ da preferência dos entrevistados é o veículo de informação mais utilizado; seguidos com 15\%, dos jornais; $7 \%$, revistas e $3 \%$, outros.

É assim que, realizando-se uma análise mais profunda dessas entrevistas mostra-se que a percepção que prevaleceu entre os moradores, principalmente entre os pequenos agricultores, é de que as reservas legais são um obstáculo às atividades produtivas da região.

Portanto, não é de estranhar que a referência, para esses entrevistados, sobre proteção do meio ambiente, é quase sempre negativa. Porque, na maioria das vezes, tal preservação lhes tira o ganho de produzir mais para sustentar a família.

Separar sociedade da natureza, ou restringi-la do uso de seus recursos, ressalta a importância da reflexão sobre "natureza e sociedade", mas, para as populações que apresentam uma relação estreita com o ambiente natural e que dele dependam, econômica e socialmente, acentuam-se enormemente 
os conflitos (CORRÊA, 2006).

Ao serem questionados sobre a renda mensal, 93\% dos proprietários rurais possuem renda de $\mathrm{R} \$ 1.000,00$ a $\mathrm{R} \$ 5.000,00$, caracterizando-os de acordo com o SEBRAE (2012) como pequenos produtores; $6 \%$, de $\mathrm{R} \$$ $6.000,00$ a $10.000,00$ e $1 \%$ responderam que suas renda variam mensalmente. Ainda é importante relatar que $73 \%$ possuem outros tipos de rendas que complementam seu orçamento; 19\% possuem apenas a renda relativa à atividade agrícola e $8 \%$ não informaram.

Tais informações podem levar à dedução que uma pequena renda, pouca instrução e acesso restrito aos meios de comunicação fazem com que esses proprietários desconheçam a legislação.

De fato, Campos Júnior (2004) ressalta que os cidadãos brasileiros em geral desconhecem vários de seus direitos e isso se faz mais presente nas classes de mais baixa renda, ou de menor nível de instrução, por terem elas menor acesso aos meios de comunicação de massa.

Observou-se que a vegetação original do município, como em todos os espaços mais humanizados da superfície terrestre, foi em grande parte retirada para dar lugar às pastagens e ao cultivo de café e de outras culturas.

Pôde-se constatar que as propriedades com áreas de 0,5 a 2 hectares possuem 53\% de suas áreas plantadas; de 2 a 4 hectares destinam $34 \%$ das áreas plantadas, de 4 a 7 hectares possuem 3\%; de 7,1 a 9 hectares destinam 6\%; acima de 9 hectares, $4 \%$ e $1 \%$ não informou.

Analisando as declarações dos produtores rurais, observou-se que existem poucos remanescentes florestais em todas as propriedades que participaram da pesquisa, e quase sempre esses remanescentes estão localizados nos topos de morros, pois segundo os produtores, essas áreas são mais difíceis de acessar e os solos são de pior qualidade. Nas propriedades de menores hectares, esses locais de mata nativa acabam por reduzir ainda mais a área destinada e considerada como Reserva Legal.

Sobre a instituição da Reserva Legal "lesar" o agricultor, é importante que foi aprovada na Câmara dos Deputados a Medida Provisória n. $571 / 2012$, a qual regulamenta o novo Código Florestal Brasileiro e dispõe que a recomposição da APP onde existir atividade consolidada anterior a 22 de julho de 2008, será menor para imóveis maiores. O replantio também poderá ser 
feito com árvores frutíferas, tanto na APP quanto na reserva legal. Em vez de 20 metros, a APP em torno de rios com até 10 metros de largura poderá ser de 15 metros. A exigência menor abrange imóveis de até 15 módulos fiscais. Nos casos de tamanho maior da propriedade ou do rio, o mínimo exigido de faixa de proteção passou de 30 para 20 metros e deverá atender à determinação do Programa de Regularização Ambiental (PRA), conduzido pelos Estados. A chamada "escadinha" não teve mudanças para as pequenas propriedades (até quatro módulos). Independentemente da largura dos rios, imóveis com até um módulo fiscal devem recompor a APP com cinco metros em torno do curso d'água. Se maior que um módulo e de até dois módulos, a recomposição deverá ser de oito metros e de 2 a 4 módulos fiscais, a recomposição é de 15 metros.

\section{CONCLUSÕES}

Nas condições em que se desenvolveu este trabalho, concluiu-se que: a propriedade rural cumpre com a sua função social quando se torna produtiva sem agredir ao meio ambiente. Sua utilização deve ser feita de forma racional e adequada, visando à manutenção do equilíbrio ecológico e à garantia da saúde, da qualidade de vida e do bem-estar social e econômico de seus proprietários e daqueles que nela trabalham, bem como de suas famílias. O não cumprimento da função social torna a propriedade rural passível de desapropriação para fins de reforma agrária.

Assim, mostra-se bem clara a necessidade de haver um incentivo para o produtor, para que o mesmo possa efetivar as áreas correspondentes à legislação, e dessa forma não apenas cumprir com a lei, mas também preservar o ambiente.

$O$ que se recomenda é a necessidade de que os programas e as políticas de implantação da Reserva Legal devem buscar, além de um maior controle e punição daqueles que não respeitam a legislação, integrar essas ações a outras medidas, como programas de educação para o produtor rural com enfoque nos princípios da agroecologia e no retorno econômico que o manejo adequado da Reserva Legal poderá trazer, tendo presente a realidade de cada município e região.

\section{REFERÊNCIAS}

CAMPOS JÚNIOR, Raimundo Alves de. $O$ conflito entre o direito de propriedade e o meio ambiente. 
Curitiba: Juruá, 2004.

CORRÊA; J. B. L. Quantificação das áreas de preservação permanentes e reserva legal e de seus impactos econômicos na Bacia de Rio Pomba em Minas Gerais. Viçosa:

Universidade Federal de Viçosa, junho de 2006.

IBGE - INSTITUTO BRASILEIRO DE GEOGRAFIA E ESTATÍSTICA - IBGE. Censo Agropecuário 2006 Resultados preliminares. Disponível em: http://www.ibge.gov.br/home/estatistica/econ omia/agropecuaria/censoagro/2006/agropecua rio.pdf. Acesso em: 06 jan. 2012.

RODRIGUES, E.C. Análise sobre o cumprimento da obrigatoriedade da reserva legal florestal. 2007, 109f.

(Dissertação). Araraquara: Centro

Universitário de Araraquara, 2007.

SEBRAE - SERVIÇO BRASILEIRO DE

APOIO ÀS MICRO E PEQUENAS EMPRESAS - Perfil do produtor rural estudos e pesquisas- Julho/2012- Disponível em:

<http://www.biblioteca.sebrae.com.br/bds/bds .nsf/471BA52CD920DC1083257A5B0041B8 F5/\$File/NT000480C6.pdf>. Acesso em: 9 set. 2012.

SENADO FEDERAL DO BRASIL. S.FED. Código Florestal: governo facilita regularização de pequenos produtores. Jus Brasil, 29 maio de 2012b. Disponível em: < http://nota-

dez.jusbrasil.com.br/noticias/3134449/sfedcodigo-florestal-governo-facilitaregularizacao-de-pequenos-produtores $>$. Acesso em 14 nov. 2012.

SENADO FEDERAL DO BRASIL. Comissão Diretora. Parecer $\mathrm{N}^{\circ} 1.358$, de 2011. Redação final do Substitutivo do Senado ao Projeto de Lei da Câmara $n^{\circ} 30$, de 2011 ( ${ }^{\circ}$ 1.876, de 1999, na Casa de origem). Diário Oficial do Senado, Brasília, DF, 8 dez. 2011.
SIFUENTES, Jefferson Prado. Reserva legal: o direito à propriedade e a desapropriação, 2012 48f. (monografia). Universidade José do Rosário Vellano/ UNIFENAS, Alfenas, 2012. 